\title{
Development of a Powder Wettability Evaluation Technique by Analyzing the Increase in Internal Pressure due to Capillary Suction of Closed Powder Bed -Effect of Powder-Bed-Preparation Method and Powder Surface Area Estimation Method-*1
}

\author{
Takamasa Mori ${ }^{1, * 2}$, Keita Ohno ${ }^{2}$, Takumi Suzuki ${ }^{2}$, Hiroshi Satone ${ }^{3}$ and JunIchiro Tsubaki ${ }^{4}$ \\ ${ }^{1}$ Department of Chemical Science and Technology, Hosei University, Tokyo 184-8584, Japan \\ ${ }^{2}$ Major in Applied Chemistry, Graduate School of Hosei University, Tokyo 184-8584, Japan \\ ${ }^{3}$ Department of Chemical Engineering and Material Science, Graduate School of Engineering, University of Hyogo, \\ Himeji 671-2280, Japan \\ ${ }^{4}$ Nagoya Industrial Science Research Institute, Nagoya 460-0008, Japan
}

Evaluation of powder wettability is important to prepare well dispersed slurries. Therefore, in this study, a technique for evaluating powder wettability was developed to analyze the increase in the internal pressure of a closed powder bed due to capillary suction to determine the contact angle of the powder. The effect of the powder-bed-preparation method and powder surface area estimation method on the determined value of the contact angle was discussed. We demonstrated that the improved air permeation test proposed in this research can accurately determine the powder surface area, resulting in a faithful determination of the contact angle of the powder. It was also shown that compression under the shearing method could result in a denser and more homogeneous powder bed when compared to the conventional tapping method, indicating high reproducibility for estimating the contact angle. [doi:10.2320/matertrans.MT-Y2021002]

(Received May 27, 2021; Accepted July 29, 2021; Published September 25, 2021)

Keywords: powder wettability, contact angle, powder bed, capillary suction, compression under shearing

\section{Introduction}

The wettability of particulate matter is an important physical property for controlling particle dispersion in liquids. Generally, wettability is defined by the contact angle. Wettability can be evaluated using several methods. ${ }^{1-3)}$ For example, the image analysis method, in which the morphology of a droplet is directly observed, is often used in cases involving bulk bodies with a large flat surface. However, this method cannot be applied to fine particles. Another method for particles, in which the morphology of a droplet is observed by dropping it onto a packed powder bed, is occasionally conducted. However, it is still difficult to evaluate particle wettability because the dropped liquid penetrates easily into the powder bed, thereby changing its morphrogy. ${ }^{1)}$

Hence, to evaluate the wettability of a particle, the penetration of liquid into a powder bed has been analyzed, ${ }^{1-3)}$ and some relevant devices have been developed and are available commercially. In most studies, the time change of a liquid mass penetrating a powder bed is measured (this method is referred to as the penetration weight method). However, in a few journals, ${ }^{4,5)}$ technical reports, ${ }^{6)}$ and Japanese patents ${ }^{7,8)}$ related to this method, some of the problems mentioned below occur in both the measurement and analysis methods. First, the data were analyzed using the following Washburn's equation, even though liquid penetrated in the vertical direction for all the devices used in the abovementioned studies.

\footnotetext{
${ }^{* 1}$ This Paper was Originally Published in Japanese in J. Jpn. Soc. Powder Powder Metallurgy 67 (2020) 629-640.

${ }^{* 2}$ Corresponding author, E-mail: tmori@ hosei.ac.jp
}

$$
\begin{gathered}
\pi d \gamma \cos \theta=8 \pi \mu \beta^{2} \frac{\mathrm{d} h}{\mathrm{~d} t} h \\
W^{2}=\frac{(S \varepsilon \rho)^{2} d \gamma \cos \theta}{4 \mu} t
\end{gathered}
$$

Here, $d[\mathrm{~m}]$ is the capillary diameter of the void in the powder bed, $\gamma\left[\mathrm{N} \cdot \mathrm{m}^{-1}\right]$ the surface tension of the liquid, $\theta\left[^{\circ}\right]$ the contact angle, $\mu[\mathrm{Pa} \cdot \mathrm{s}]$ the liquid viscosity, $\beta[-]$ the tortuosity factor, $h[\mathrm{~m}]$ the depth of the penetrated liquid, $t[\mathrm{~s}]$ the penetration time, $W[\mathrm{~kg}]$ the mass of the penetrated liquid, $S$ $\left[\mathrm{m}^{2}\right]$ the cross-sectional area of the powder bed, $\varepsilon[-]$ the porosity of the powder bed, and $\rho\left[\mathrm{kg} \cdot \mathrm{m}^{-3}\right]$ the liquid density.

Washburn $^{9}$ indicated that eq. (1) expresses the force balance of liquid for horizontal liquid penetration, not vertical liquid penetration. For vertical liquid penetration, the mass of the penetrated liquid should be considered when considering the force balance of the penetrated liquid. ${ }^{9,10)}$ Hence, eq. (2), which is derived from eq. (1), cannot be applied to analyze the time change of the penetrated liquid mass for vertical liquid penetration into the powder bed. It has been reported that there is an unignorable difference between the calculated contact angles, depending on whether the mass of the penetrated liquid is considered in order to analyze the vertical liquid penetration into the powder bed. ${ }^{11)}$

In addition, as will be explained in detail later, the advancing contact angle can be determined by analyzing the data during liquid penetration. In other words, it is incorrect to assume that the advancing contact angle is constant even though it changes with the liquid penetration velocity, although this was assumed in previous data analyses. Therefore, to evaluate particle wettability based on vertical liquid penetration into the powder bed, it is necessary to (1) analyze the data using the motion equation while considering the mass of the penetrated liquid and (2) be aware that the 
advancing contact angle can be determined by analyzing the data during liquid penetration while considering changes in the liquid penetrating velocity. ${ }^{12,13)}$

Meanwhile, because the capillary force in the fine powder bed is large, a large powder bed with a height of several meters is required to attain dynamic equilibrium under atmospheric pressure. This means that, it is difficult to obtain the contact angle of vertical liquid penetrating into the powder bed under atmospheric pressure, even though the analysis method is correct. The only contact angle can be obtained via liquid penetration under pressure, ${ }^{14,15)}$ however, the advancing contact angle cannot be obtained.

Hence, the advancing contact angle and the contact angle were determined by analyzing the pressure increase in a closed powder bed associated with liquid penetration, as reported by Deralo et al. ${ }^{12)}$ In this paper, ${ }^{12)}$ instead of measuring the weight, the authors measured the air pressure increase in the closed powder bed due to liquid penetration to analyze the behavior using the following equation:

$$
\pi d \gamma \cos \theta=\frac{\pi d^{2}}{4} \rho g h+8 \pi \mu \beta^{2} \frac{\mathrm{d} h}{\mathrm{~d} t} h
$$

This equation considers the effect of the penetrated liquid mass. In addition, because the inner pressure of the powder bed increases, the contact angle can be determined without the powder bed with a height of several meters. This is one of the advantages of this method compared with conventional atmospheric measurements. However, several problems exist: (1) some inappropriate data were included, which were measured at conditions where the wall effect could not be disregarded (e.g., $500 \mu \mathrm{m}$ particles were filled in a cell with a diameter of $12.5 \mathrm{~mm}$ ), and (2) the packing fraction of the powder bed was determined by referring to the study of Hapgood et al., ${ }^{16)}$ in which the powder bed was assumed to be inhomogeneous (whereas a homogeneous powder bed is required for the evaluation of particle wettability). In that study, an air bubble was observed at the bottom of the powder bed during the initial stage of measurement. ${ }^{12)}$ This implies that the powder bed used in that study should be inhomogeneous and hence not suitable for wettability characterization, thereby rendering the results unreliable. Moreover, a relatively large buffer was connected to the device to suppress fluctuations due to the inhomogeneity of the powder bed; ${ }^{12)}$ consequently, the device size increased and the sensitivity decreased.

Therefore, the objective of this study is to develop a reliable method to evaluate the wettability by improving the preparation method of the powder bed for measuring the pressure increase associated with liquid penetration in a closed powder bed.

Furthermore, the specific surface area of the particle must be determined to calculate the contact angle from the pressure increase due to liquid penetration into the powder bed. In this study, a method is proposed that can easily determine the specific surface area of the powder layer used for wettability evaluation. The effect of the method of determining the specific surface area of the powder layer on the value of the contact angle will be investigated. One of the typical methods for determining the specific surface area of a particle is known as the BET method; ${ }^{17)}$ however, it is not suitable for this study because the surface area of micropores is included in the BET method, whereas the micropores do not contribute to liquid penetration in this study. In previous reports regarding the determination of particle wettability, the specific surface area of the particle was calculated based on the average particle size $e^{4,13)}$ or determined using the air permeability method. ${ }^{5,18)}$ Generally, the conventional air permeability method is difficult to use; therefore, the specific surface area is often calculated based on the average particle size. When calculating the specific surface area based on the particle size, the specific surface area shape factor is necessitated; however, it is difficult to determine precisely for all types of powders. Therefore, the specific surface area shape factor of a spherical powder is typically used. The validity of contact angles determined based on a specific surface area calculated from the particle size is yet to be elucidated.

Herein, we propose a simple method to determine the real specific surface area of a powder bed for wettability measurement, and the effect of the specific surface area determination method on the contact angle is discussed.

\section{Experiment}

\subsection{Effect of particle packing method on particle wettability evaluation}

\subsubsection{Materials}

The raw materials used in this study were $\mathrm{Al}_{2} \mathrm{O}_{3}$ (AS-50, SHOWA DENKO K. K., nominal particle size $=9 \mu \mathrm{m})$, and $\mathrm{CaCO}_{3}$ (JIS test powder 1 class 16, nominal particle size $=6 \mu \mathrm{m})$. These powders were stored in a desiccator with silica gel for $24 \mathrm{~h}$. The test solvent used to wet the powder was deionized water.

\subsubsection{Particle packing method}

The powder bed for the wettability test was prepared via two different methods: the conventional tapping method and our developed shearing and compressing method. ${ }^{19,20)}$ For the tapping method, particles were placed into a cell with a diameter and depth of $10 \mathrm{~mm}$; subsequently, the cell was dropped freely from a height of approximately $10 \mathrm{~mm}$ for 100 or 300 times, as shown in Fig. 1.

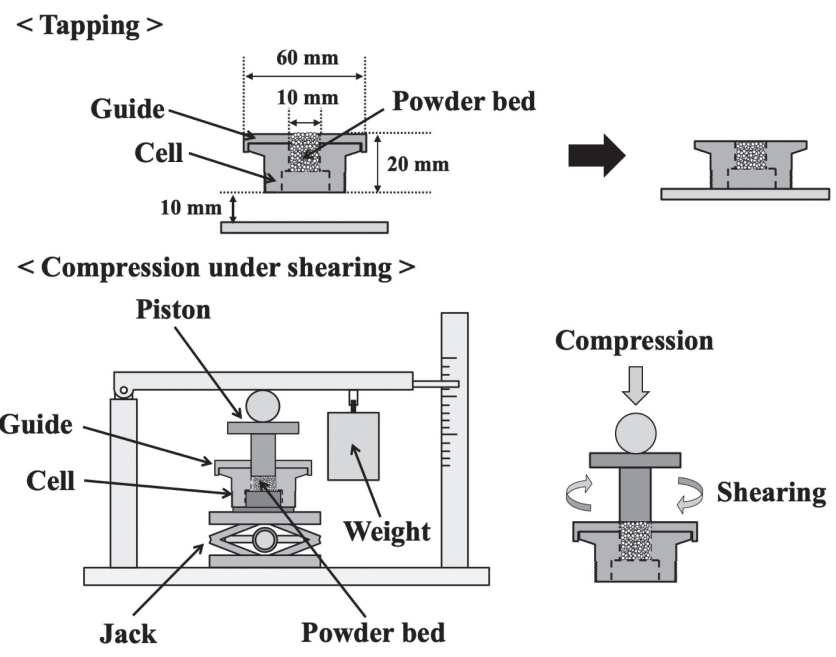

Fig. 1 Schematic illustration of powder filling methods. 


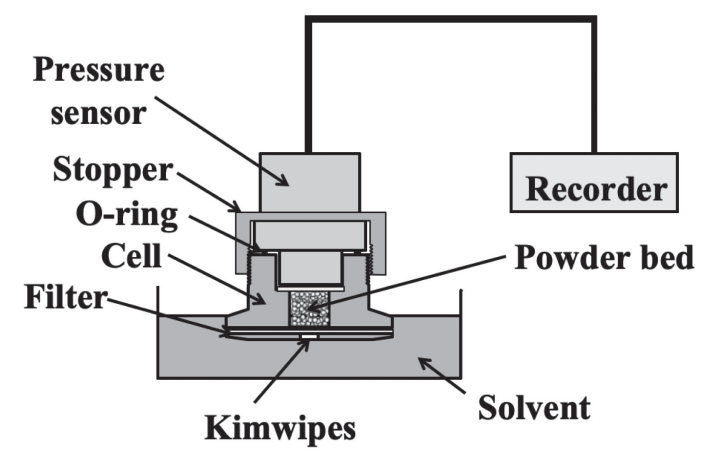

Fig. 2 Schematic of the apparatus for powder wettability measurement.

For the shearing and compressing method, particles were filled into the cell as the same way for tapping method; subsequently, the cell was mounted on a shearing and compressing device, as shown in Fig. 1. The powder bed was compressed at 0.2 or $0.4 \mathrm{MPa}$ by a piston while it was moved from side to side by shearing. If the powder bed height decreases by performing the procedure above, then other particles are added into the cell and the procedure above is repeated until the powder bed height remains constant. This shearing procedure is expected to render the powder bed homogeneous owing to the rearrangement of the particles. ${ }^{19,20)}$ To verify the repeatability, the test was performed five times for each experimental condition.

\subsubsection{Particle wettability evaluation}

Figure 2 shows a schematic illustration of the apparatus used for particle wettability characterization. A cell comprising a powder bed, prepared via the method above, was mounted on the apparatus. At that time, a glass fiber filter (GC-50, Toyo Roshi Kaisha, Ltd., particle cut size $=0.5 \mu \mathrm{m}$, filter thickness $=0.19 \mathrm{~mm}$ ) was placed on the bottom of the powder bed. The filter was filled with deionized water as it was placed it into the container with deionized water; next, it was removed from the container, and additional water was drained prior to the test. A lid was installed under the filter and then fixed using a clamp. Kimwipe containing deionized water was set in the center of the lid; hence, the powder bed can draw water from the reservoir tank when it is dipped into the reservoir tank. The powder bed set in the cell was placed in the reservoir tank with deionized water, and the inner pressure of the cell was monitored using a pressure sensor (HXV-500KP-02-V, SENSEZ Corp.). The contact angle and the advancing contact angle can be obtained by analyzing the pressure change in the cell due to liquid penetration, based on the theory presented in the next section.

\subsection{Method to determine particle specific surface area \\ 2.2.1 Materials}

To validate the method for determining the particle specific surface area, the following experiment was performed using three types of powders: glass beads (JIS standard powders, GBL-40 with a nominal particle size of $40 \mu \mathrm{m}$, GBM-20, GBM-40 with nominal particle sizes of 20 and $40 \mu \mathrm{m}$ ), abrasive alumina powders (WA\#1500, 1200, 700, and 500 with nominal particle sizes of $8,9.5,17$, and $25 \mu \mathrm{m}$, respectively, FUJIMI Inc.), and graphite powder (SG-BH8 with a nominal particle size of $8 \mu \mathrm{m}$, Ito Graphite Co., Ltd.).

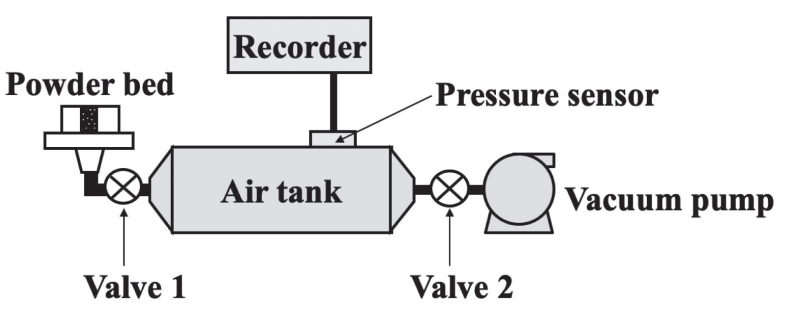

Fig. 3 Schematic of the apparatus for air permeability method.

These powders were stored in a desiccator with silica gel for $24 \mathrm{~h}$. The test solvent used to wet the powder was deionized water.

\subsubsection{Air permeation method}

To calculate the contact angle of the powder, its specific surface area must be determined. In this study, the specific surface area of the powder was determined based on the following procedure, which entailed air permeation to the powder bed. The conventional air permeation method has already been described comprehensively in a previous paper. ${ }^{18)}$ In this study, we used the same powder bed used for the wettability test and improved the device and procedure to determine the specific surface area.

Figure 3 shows a schematic illustration of the experimental apparatus. First, the inner pressure of the tank was decreased by approximately $10 \mathrm{kPa}$ below atmospheric pressure using a vacuum pump. The powder bed prepared, as shown in Section 2.1.2, was set to the device, and then the air valve was opened. Air permeated into the tank through the powder bed owing to pressure drop. The time change of the pressure in the tank was measured using a pressure sensor. The pressure was measured until the pressure in the tank became equal to the atmospheric pressure. The specific surface area of the particles was calculated from the pressure change based on the theory described in the next section. For comparison, the nominal particle size $D_{\mathrm{p}}[\mathrm{m}]$, measured via the electric resistance method, ${ }^{21)}$ was used to determine the specific surface area, $S_{\mathrm{v}}\left[\mathrm{m}^{-1}\right]$, which was calculated as follows: $:^{22)}$

$$
S_{\mathrm{v}}=\frac{6}{D_{\mathrm{p}}}
$$

The contact angles determined using the specific surface areas obtained from the air permeation method and the nominal particle size method were compared.

\subsubsection{Particle wettability evaluation}

After measuring the specific surface area, as detailed in Section 2.2.2, the powder bed was set in the apparatus for wettability measurement, as shown in Fig. 2. The pressure change in the cell was measured based on the procedure described in Section 2.1.3; subsequently, the contact angle was determined based on the theory presented in the next section.

\section{Theory}

\subsection{Determination of contact angle}

The advancing contact angle and the contact angle were determined based on the pressure change in the closed powder bed (as shown in Fig. 4) due to liquid penetration. 


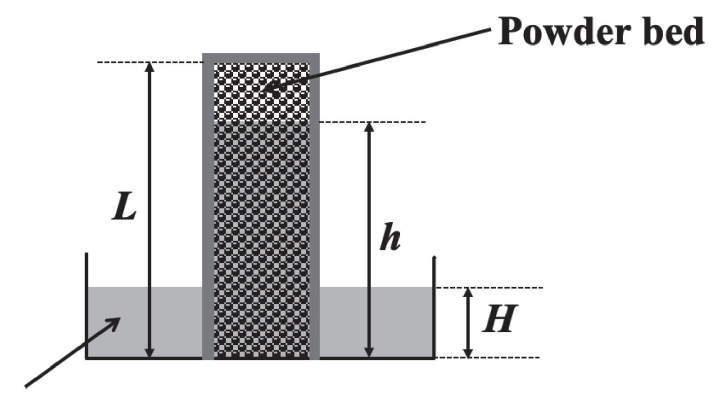

Solvent

Fig. 4 Schematic illustration of liquid penetration for a closed powder bed.

The void in the powder bed with a packing fraction $\phi[-]$ can be replaced by a bundle of capillaries with a diameter of $r[\mathrm{~m}]$, which is expressed as follows: $\left.{ }^{23}\right)$

$$
r=\frac{2(1-\phi)}{\phi S_{\mathrm{v}}}
$$

When the liquid penetrates the closed powder bed, the rate of the rise of the liquid can be expressed by the following equation, in which the mass of the penetrated liquid is considered.

$$
\pi r^{2}\left(\rho g h+\frac{8 \mu h \dot{h}}{r^{2}}+p\right)=2 \pi r \gamma \cos \theta+\pi r^{2}(\rho g H+P)
$$

Here, $\rho\left[\mathrm{kg} \cdot \mathrm{m}^{-3}\right]$ is the liquid density, $\mu[\mathrm{Pa} \cdot \mathrm{s}]$ the liquid viscosity, $h[\mathrm{~m}]$ the height of the permeated liquid level, $\dot{h}$ $\left[\mathrm{m} \cdot \mathrm{s}^{-1}\right]$ the rate of the rise of the liquid level, $\gamma\left[\mathrm{N} \cdot \mathrm{m}^{-1}\right]$ the surface tension of the liquid, $\theta\left[^{\circ}\right]$ the contact angle, and $H$ [m] the level of the solvent in the tank.

The following equations were established for the air in the powder bed using Boyle's law:

$$
\begin{gathered}
h=\frac{p-P}{p} L \\
\dot{h}=\frac{P L}{p^{2}} \dot{p}
\end{gathered}
$$

Here, $L[\mathrm{~m}]$ is the height of the powder bed. Subsequently, the height and liquid rising velocity terms in eq. (6) can be replaced by the pressure, $p[\mathrm{~Pa}]$ and its rate of increase in the cell, $\dot{p}\left[\mathrm{~Pa} \cdot \mathrm{s}^{-1}\right]$, respectively. By rearranging eq. (6), the following equation is obtained:

$$
\cos \theta=\frac{r}{2 \gamma}\left\{\left(\rho g+\frac{8 \mu}{r^{2}} \frac{P L}{p^{2}} \dot{p}\right) \frac{p-P}{p} L+p-P-\rho g H\right\}
$$

Therefore, the advancing contact angle and the contact angle can be obtained by substituting the pressure and its increasing rate in the cell at each measured time during liquid penetration into eq. (9).

\subsection{Determination of specific surface area by air permeation}

The specific surface area of the powder bed term in eq. (5) can be determined using an improved air permeation method.

For the apparatus, as shown in Fig. 3, the powder bed was mounted to the evacuated tank and then the valve was opened. Consequently, air permeated into the tank through the powder bed owing to the pressure difference. At that time, the flow rate of air can be written as follows:

$$
-\frac{\mathrm{d} n}{\mathrm{~d} t}=\frac{p-P}{r_{\mathrm{p}}+r_{\mathrm{f}}}
$$

Here, $n[\mathrm{~mol}]$ is the molar number of air, $t[\mathrm{~s}]$ the time after opening the valve, $p[\mathrm{~Pa}]$ the air pressure in the tank, $P[\mathrm{~Pa}]$ the atmospheric pressure, $r_{\mathrm{p}}\left[\mathrm{Pa} \cdot \mathrm{s} \cdot \mathrm{mol}^{-1}\right]$ the flow resistance of the powder bed, and $r_{\mathrm{f}}\left[\mathrm{Pa} \cdot \mathrm{s} \cdot \mathrm{mol}^{-1}\right]$ the flow resistance of the piping system.

Assuming that air is an ideal gas, the following equations are applicable.

$$
\begin{gathered}
n=\frac{p V}{R T} \\
\mathrm{~d} p=\frac{R T}{V} \mathrm{~d} n
\end{gathered}
$$

Here, $V\left[\mathrm{~m}^{3}\right]$ is the volume of the tank, and $T[\mathrm{~K}]$ is the air temperature.

Based on eqs. (10) and (12), the following equation can be derived:

$$
\frac{\mathrm{d} p}{p-P}=-\frac{R T}{V\left(r_{\mathrm{p}}+r_{\mathrm{f}}\right)} \mathrm{d} t
$$

Integrating eq. (13) using boundary conditions $(t=0$, $\left.p=p_{0}\right)$ and $(t=t, p=p)$, the following equation can be obtained:

$$
\ln \frac{p_{0}-P}{p-P}=\frac{R T}{V\left(r_{\mathrm{p}}+r_{\mathrm{f}}\right)} t
$$

Therefore, by plotting time $t$ and the value of the left side of eq. (14), the plot should be distributed on a straight line, and the total flow resistance (the sum of the resistances of the powder bed and pipe system) can be determined by the slope of the straight line. If the resistance of the pipe system $r_{\mathrm{f}}$ is determined by a blank test in advance, then the resistance of the powder bed, $r_{\mathrm{p}}$, can be determined.

Meanwhile, when a fluid with viscosity $\mu[\mathrm{Pa} \cdot \mathrm{s}]$ penetrates into a powder bed with a void fraction of $\varepsilon[-]$ and a height of $L[\mathrm{~m}]$ by applying a pressure difference $\Delta P[\mathrm{~Pa}]$, then the flow velocity of the fluid $u\left[\mathrm{~m} \cdot \mathrm{s}^{-1}\right]$ can be expressed by the following Kozeny-Carman equation: ${ }^{24)}$

$$
u=\frac{1}{k S_{\mathrm{v}}^{2} \mu L} \cdot \frac{\varepsilon^{3}}{(1-\varepsilon)^{2}} \cdot \Delta P
$$

Here, $k$ is the Kozeny constant, which has been reported widely to be $k=5 .^{25)}$ Substituting the conditions above into this equation, we can obtain the following equation:

$$
-\frac{1}{A} \frac{\mathrm{d} q}{\mathrm{~d} t}=\frac{1}{5 S_{\mathrm{v}}^{2} \mu L} \cdot \frac{(1-\phi)^{3}}{\phi^{2}} \cdot \frac{r_{\mathrm{p}}}{r_{\mathrm{p}}+r_{\mathrm{f}}}(p-P)
$$

Here, $q\left[\mathrm{~m}^{3}\right]$ is the volume of air flowing into the tank, and $\phi[-]$ is the packing fraction of the powder bed. In our experimental conditions shown above, we can assume the following relationship between the volume and molar number of air because the applied pressure difference did not exceed $10 \mathrm{kPa}$ :

$$
\mathrm{d} q=\frac{22.4 T}{273} \times 10^{-3} \mathrm{~d} n
$$



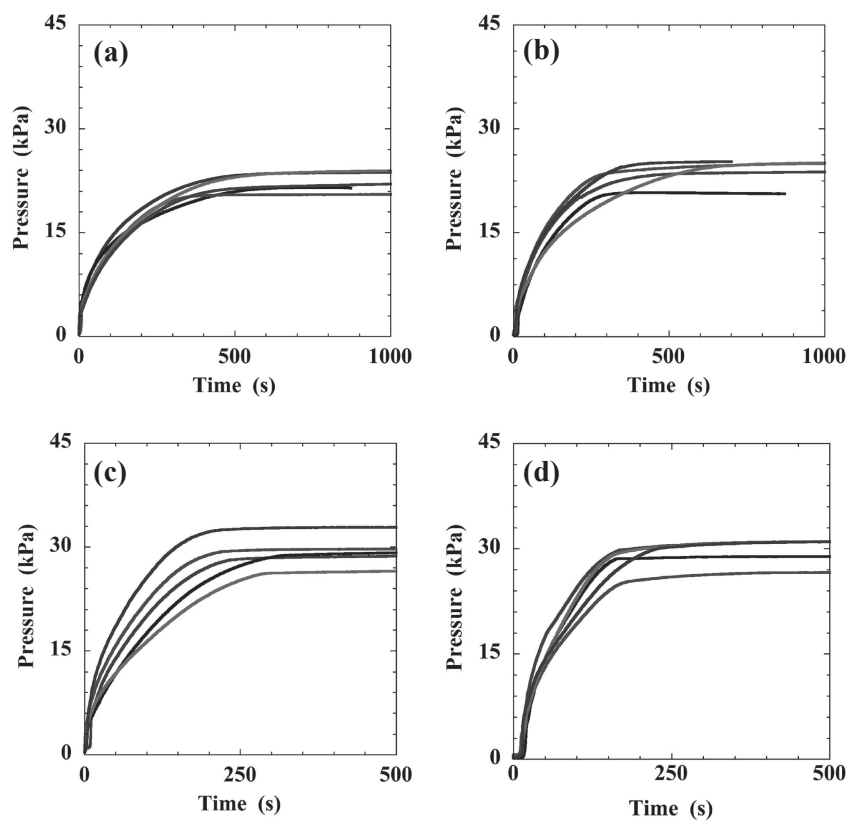

Fig. 5 Time changes of the pressure by liquid penetration for $\mathrm{Al}_{2} \mathrm{O}_{3}$ powder. Samples are tapping (a) $n=100$, (b) $n=300$, and compression under shearing (c) $p=0.2 \mathrm{MPa}$, (d) $p=0.4 \mathrm{MPa}$.

Combining eqs. (16) and (17), the following equation can be obtained:

$$
-\frac{\mathrm{d} n}{\mathrm{~d} t}=\frac{273 \times 10^{3}}{22.4 T} \cdot \frac{A(1-\phi)^{3} \cdot \frac{r_{\mathrm{p}}}{r_{\mathrm{p}}+r_{\mathrm{f}}} \cdot(p-P)}{5 \phi^{2} S_{\mathrm{v}}^{2} \mu L}
$$

Therefore, based on eqs. (10) and (18), we can obtain the following equation and calculate the specific surface area of the powder:

$$
S_{\mathrm{v}}=\left\{\frac{r_{\mathrm{p}} A(1-\phi)^{3}}{0.112 \phi^{2} \mu L} \cdot \frac{273}{T}\right\}^{1 / 2}
$$

\section{Results and Discussion}

\subsection{Effect of powder packing method on powder wettability characterization}

Figures 5 and 6 show the time change of the air pressure in the tank for $\mathrm{Al}_{2} \mathrm{O}_{3}$ and $\mathrm{CaCO}_{3}$, respectively. For both powders, the pressure increased due to liquid penetration and reached the equilibrium state in approximately $150 \mathrm{~s}$ when it was shorter, or approximately $1,000 \mathrm{~s}$ when it was longer. Figures 7 and 8 show the advancing contact angle and contact angle determined by analyzing the results of Figs. 5 and 6 based on eq. (9), respectively. As shown in these figures, the advancing contact angle decreased with time and finally reached a constant value, which corresponded to the contact angle. This phenomenon can be interpreted as follows: As an example, the case of $\mathrm{Al}_{2} \mathrm{O}_{3}$ (tapping times, $\mathrm{n}=100$ ) is shown in Fig. 9. The rate of rising of the water level in the powder bed decreased as the pressure in the cell increased owing to water penetration. Hence, the advancing contact angle decreased with time, i.e., the shape of the formed meniscus changed with time because the velocity of the water decreased with time. The advancing contact angle
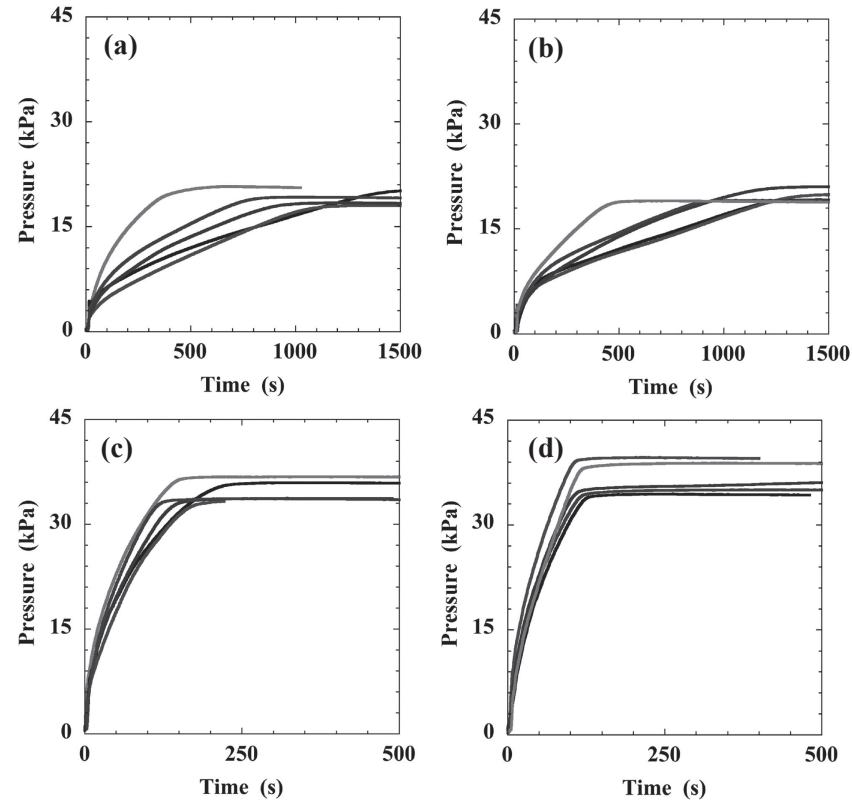

Fig. 6 Time changes of the pressure by liquid penetration for $\mathrm{CaCO}_{3}$ powder. Samples are tapping (a) $n=100$, (b) $n=300$, and compression under shearing (c) $p=0.2 \mathrm{MPa}$, (d) $p=0.4 \mathrm{MPa}$.
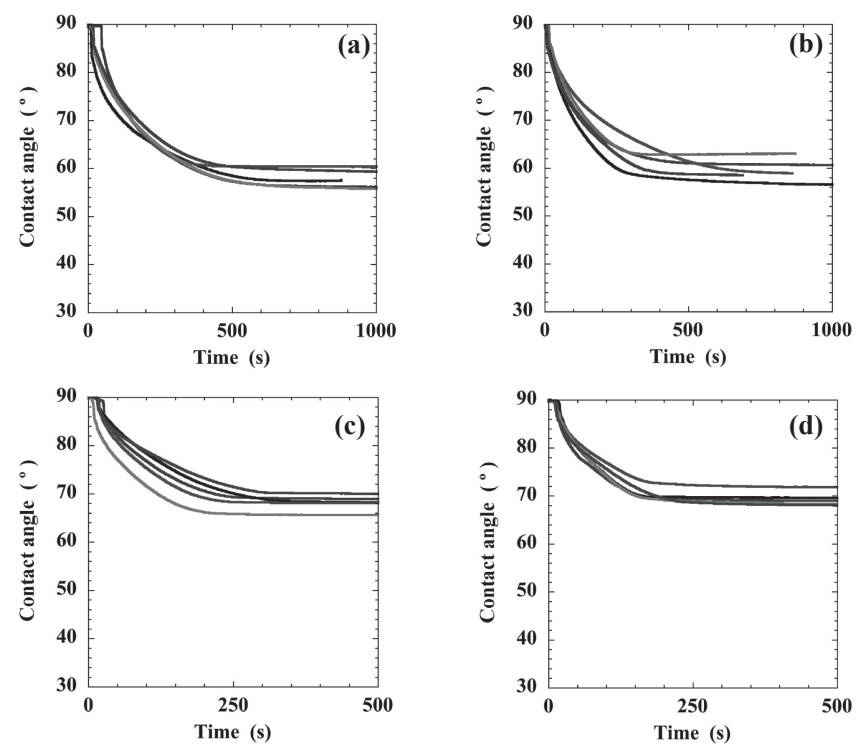

Fig. 7 Time changes of the contact angle determined by eq. (16) for $\mathrm{Al}_{2} \mathrm{O}_{3}$ powder. Samples are tapping (a) $n=100$, (b) $n=300$, and compression under shearing (c) $p=0.2 \mathrm{MPa}$, (d) $p=0.4 \mathrm{MPa}$.

became the largest at the initial stage of the test, where the velocity of water was the greatest; subsequently, it decreased with the velocity of water as the pressure in the cell increased. Finally, when the water penetration stopped owing to the increased pressure in the cell, the advancing contact angle reached equilibrium, which corresponded to the contact angle. Therefore, it is concluded that both the advancing contact angle during liquid level rise and the contact angle at equilibrium can be determined using the proposed method.

To investigate the effect of the particle packing method on powder wettability evaluation, the contact angle at equilibrium determined using the above method is discussed. Tables 1 and 2 summarize the average, standard deviation, 

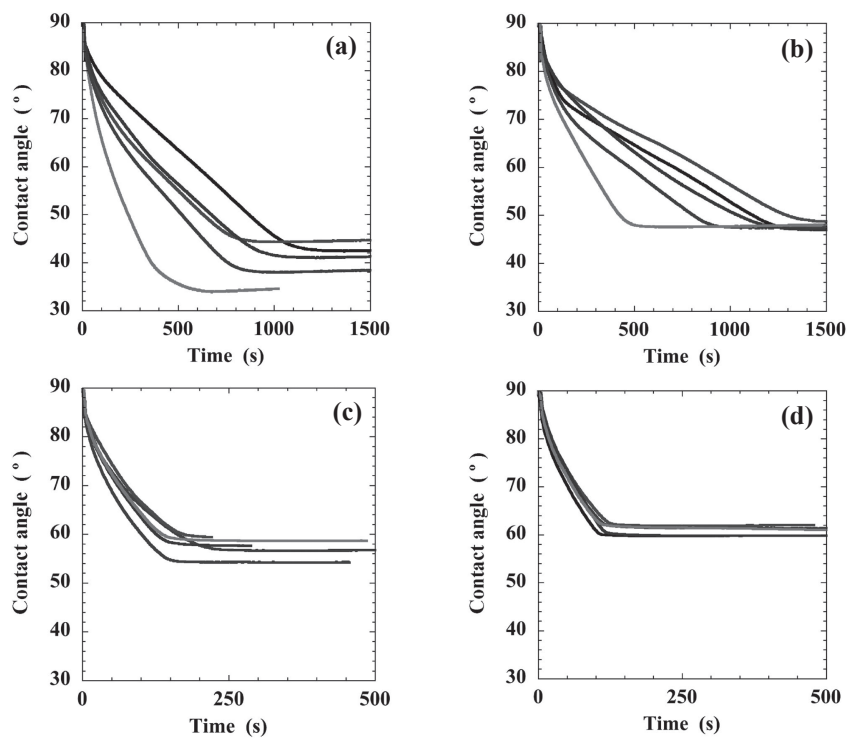

Fig. 8 Time changes of the contact angle determined by eq. (16) for $\mathrm{CaCO}_{3}$ powder. Samples are tapping (a) $n=100$, (b) $n=300$, and compression under shearing (c) $p=0.2 \mathrm{MPa}$, (d) $p=0.4 \mathrm{MPa}$.

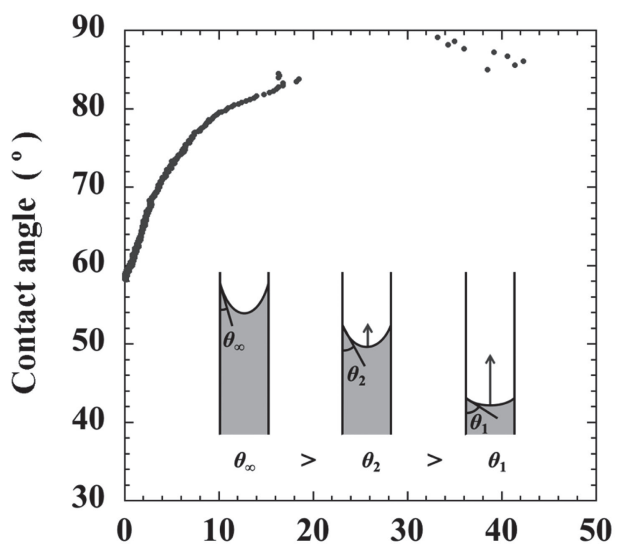

Rising velocity of liquid surface $(\mu \mathrm{m} / \mathrm{s})$

Fig. 9 Relationship between contact angle and rising velocity of liquid surface for $\mathrm{Al}_{2} \mathrm{O}_{3}$ powder, tapping $n=100$.

Table 1 Contact angles and packing fractions of $\mathrm{Al}_{2} \mathrm{O}_{3}$.

\begin{tabular}{ccccccccc}
\hline & & \multicolumn{3}{c}{ contact angle $\left(^{\circ}\right.$ ) } & \multicolumn{3}{c}{ packing fraction $(-)$} \\
& & average & SD & CV (\%) & average & SD & CV (\%) \\
\hline \multirow{2}{*}{ tapping } & $n=100$ & 57.9 & 1.9 & 3.4 & 0.462 & 0.0076 & 1.6 \\
& $n=300$ & 59.6 & 2.4 & 4.0 & 0.494 & 0.0080 & 1.6 \\
$\begin{array}{c}\text { compression } \\
\text { under } \\
\text { shearing }\end{array}$ & $0.2 \mathrm{MPa}$ & 68.3 & 1.6 & 2.4 & 0.618 & 0.0032 & 0.5 \\
\hline
\end{tabular}

and coefficient variation of the contact angles determined for $\mathrm{Al}_{2} \mathrm{O}_{3}$ and $\mathrm{CaCO}_{3}$, respectively. For both powders, the average contact angle increased and the coefficient variation decreased in the shearing and compressing method, compared with the conventional tapping method. From the packing fraction of the powder bed shown in Tables 1 and 2, the packing fraction increased and its coefficient variation decreased in the shearing and compressing method,
Table 2 Contact angles and packing fractions of $\mathrm{CaCO}_{3}$.

\begin{tabular}{ccccccccc}
\hline & & \multicolumn{3}{c}{ contact angle $\left({ }^{\circ}\right)$} & \multicolumn{3}{c}{ packing fraction (-) } \\
& & average & SD & CV $(\%)$ & average & SD & CV (\%) \\
\hline \multirow{2}{*}{ tapping } & $n=100$ & 40.2 & 4.0 & 10 & 0.256 & 0.0078 & 3.0 \\
& $n=300$ & 47.7 & 0.8 & 1.7 & 0.284 & 0.0077 & 2.7 \\
$\begin{array}{c}\text { compression } \\
\text { under } \\
\text { shearing }\end{array}$ & $0.2 \mathrm{MPa}$ & 57.4 & 2.0 & 3.4 & 0.467 & 0.0049 & 1.1 \\
\hline
\end{tabular}
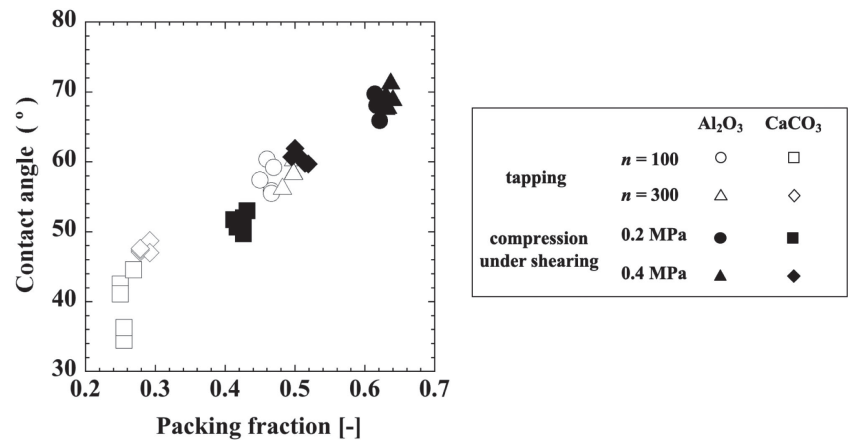

Fig. 10 Relationship between contact angle and packing fraction of powder bed.

compared with for the tapping method; this indicates that the powder bed prepared via the shearing and compressing method was denser and more homogeneous. Hence, the reproducibility of the wettability evaluation improved by preparing the powder bed using the shearing and compressing method.

Figure 10 shows the relationship between the contact angle and packing fraction of the powder bed for $\mathrm{Al}_{2} \mathrm{O}_{3}$ and $\mathrm{CaCO}_{3}$. Initially, the contact angle of a powder must be independent of the packing fraction of the powder bed because the contact angle indicates the wettability of the material to the liquid. However, as shown in Fig. 10, the contact angle increased with the packing fraction of the powder bed. This might be because the data in Fig. 10 included those from the tapping method and shearing and compressing method. In other words, the data in Fig. 10 were obtained from a powder bed with different packing fractions and homogeneities. The fact that the variation in the contact angle of the powder bed prepared via the shearing and compressing method was smaller than that of the powder bed prepared via the tapping method for both $\mathrm{Al}_{2} \mathrm{O}_{3}$ and $\mathrm{CaCO}_{3}$ supports this consideration. However, based on only the results of the shearing and compression method, the effect of the packing fraction of the powder bed on the contact angle was not disregarded. This might be due to the estimation of the capillary radius in the powder bed, i.e., the specific surface area of the powder. We will discuss this in the next section. In addition, it has been reported that the contact angle increased when the capillary radius decreased in experiments of glass tubes, although the mechanism is yet to be elucidated. ${ }^{26,27)}$ In this study, it was discovered that the contact angle increased as the capillary radius decreased; this phenomenon should be verified through further investigations. 


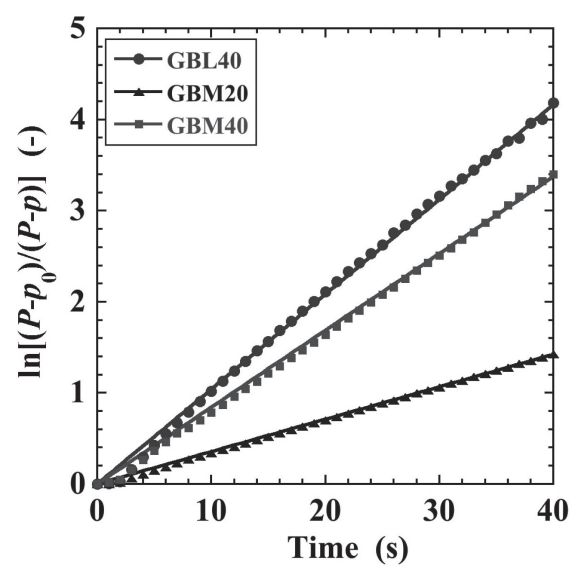

Fig. 11 Results of air permeability test for glass beads.

Table 3 Specific surface areas for glass beads.

\begin{tabular}{cccccc}
\hline Sample & $\begin{array}{c}\text { particle size } \\
(\mu \mathrm{m})\end{array}$ & $\begin{array}{c}\text { packing fraction } \\
(-)\end{array}$ & $\begin{array}{c}\text { gradient } \\
\left(\mathrm{s}^{-1}\right)\end{array}$ & $\begin{array}{c}\text { specific surface area } \times 10^{-5}\left(\mathrm{~m}^{2} / \mathrm{m}^{3}\right) \\
\text { experiment }\end{array}$ & calculation \\
\hline GBL-40 & 40 & $0.574 \pm 0.009$ & $0.104 \pm 0.006$ & $1.52 \pm 0.04$ & 1.50 \\
GBM-20 & 20 & $0.577 \pm 0.001$ & $0.033 \pm 0.001$ & $2.91 \pm 0.06$ & 3.00 \\
GBM-40 & 40 & $0.595 \pm 0.008$ & $0.086 \pm 0.007$ & $1.54 \pm 0.03$ & 1.50 \\
\hline
\end{tabular}

\subsection{Effect of determination method of specific surface area on powder wettability characterization}

Figure 11 shows the air permeation test results analyzed using eq. (14) for glass beads. The experimental results were well fitted based on the theory because the experimental results were distributed along a straight line. Table 3 shows the specific surface area obtained by substituting $r_{\mathrm{p}}$ determined from the results shown in Fig. 11 into eq. (19). For comparison, the specific surface area calculated based on the nominal particle size is shown in Table 3. For glass beads, it was expected that the specific surface areas determined via the air permeation method would correspond to those calculated from the nominal particle size because the glass beads were spherical and possessed better flowability, resulting in a dense and homogeneous powder bed. As shown in Table 3, the specific surface area obtained via the air permeation method coincided with that calculated based on the nominal particle size for all types of glass beads used in this study. This indicates that the specific surface area can be determined correctly based on the proposed improved air permeation test regardless of the materials and particle sizes.

Furthermore, Fig. 12 shows the contact angles of alumina powders with different particle sizes against deionized water. In this figure, both contact angles were plotted; one was calculated using the specific surface area determined via the air permeation test, and the other was calculated using the specific surface area calculated based on the nominal particle size. As shown in this figure, the contact angle decreased with the particle size when it was determined using the specific surface area calculated based on the nominal particle size. Considering that these alumina powders were fabricated using the same method, their surface properties should be the same; hence, that the contact angle changed with the particle size was unexpected. By contrast, the contact angle barely changed when it was determined using the specific surface

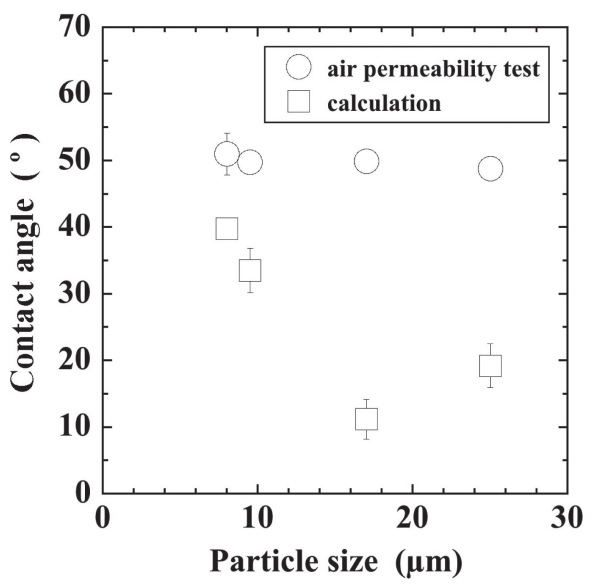

Fig. 12 Relationship between contact angle and particle size for $\mathrm{Al}_{2} \mathrm{O}_{3}$.

Table 4 Specific surface areas for $\mathrm{Al}_{2} \mathrm{O}_{3}$.

\begin{tabular}{|c|c|c|c|}
\hline \multirow{2}{*}{$\begin{array}{l}\text { particle size } \\
(\mu \mathrm{m})\end{array}$} & \multicolumn{2}{|c|}{$\begin{array}{c}\text { specific surface area } \\
\times 10^{-5}\left(\mathrm{~m}^{2} / \mathrm{m}^{3}\right)\end{array}$} & \multirow{2}{*}{$\frac{\text { calculation }}{\text { experiment }}(-)$} \\
\hline & experiment & calculation & \\
\hline 8.0 & 9.27 & 7.50 & 0.81 \\
\hline 9.5 & 7.90 & 6.32 & 0.80 \\
\hline 17 & 5.38 & 3.53 & 0.66 \\
\hline 25 & 3.62 & 2.40 & 0.66 \\
\hline
\end{tabular}

area determined via the air permeation test. Therefore, it is inferred that determining the specific surface area via the air permeation test is appropriate. To discuss the differences between the methods for determining the specific surface area comprehensively, all the specific surface areas determined are summarized in Table 4. As shown, the specific surface area calculated based on the nominal particle size was smaller than that determined via the air permeation test. Moreover, the difference between them became significant when the particle size increased. In eq. (4), which was used for calculating the specific surface area based on the nominal particle size, a spherical particle was assumed; however, the real alumina abrasive powder was not spherical, as shown by the SEM images in Fig. 13. In other words, the difference in the specific surface areas determined using each method was believed to be caused by the particle morphology. Hence, the circularity ${ }^{28,29)}$ defined in the following equation was determined from the images of particles observed via SEM.

$$
(\text { Circularity })=\frac{4 \pi A}{C^{2}}
$$

Here, $C[\mathrm{~m}]$ is the perimeter of the particle image, and $A\left[\mathrm{~m}^{2}\right]$ is the area of the particle image. The effect of particle size on circularity is shown in Fig. 14, where the circularity of each sample is the average value for 30 particles in each sample, and it is calculated using the image analysis software, Image J. As shown in this figure, the circularity decreased as the particle size increased, indicating that the particle images deviated significantly from a circular shape when the particle size increased. Therefore, the contact angle decreased as the particle size increased because the particle morphology deviated significantly from a spherical shape as the particle 

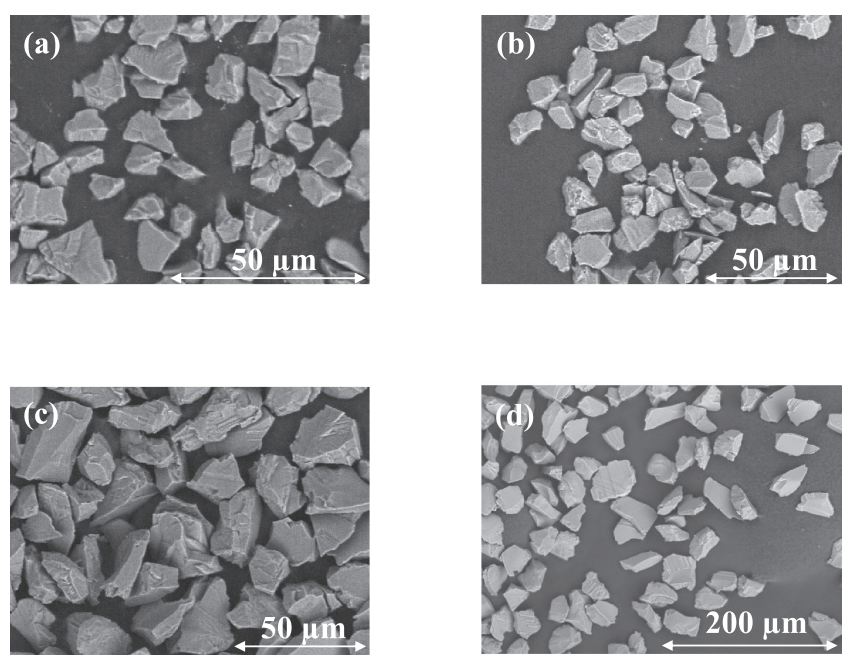

Fig. 13 SEM images of $\mathrm{Al}_{2} \mathrm{O}_{3}$, (a) 8.0 , (b) 9.5 , (c) 17 , and (d) $25 \mu \mathrm{m}$.

size increased. In other words, the specific surface area calculated from the nominal particle size was not consistent with that determined via the air permeation test because of the particle morphology.

Furthermore, Fig. 15 shows the results of the wettability evaluation, determined contact angle, and appearance of the

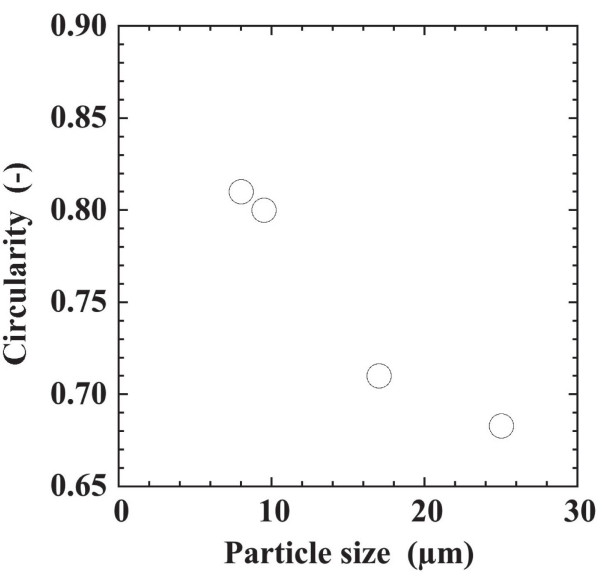

Fig. 14 Relationship between circularity and particle size for $\mathrm{Al}_{2} \mathrm{O}_{3}$.

dispersing test for graphite powder. In the dispersing test, graphite powder was added to deionized water without stirring. Both contact angles were calculated based on the pressure change shown in Fig. 15, using eq. (9) and the specific surface area calculated from the nominal particle size or specific surface area determined via the air permeation test. When using the specific surface area calculated based on the nominal particle size, $7.50 \times 10^{5} \mathrm{~m}^{-1}$, the contact angle at
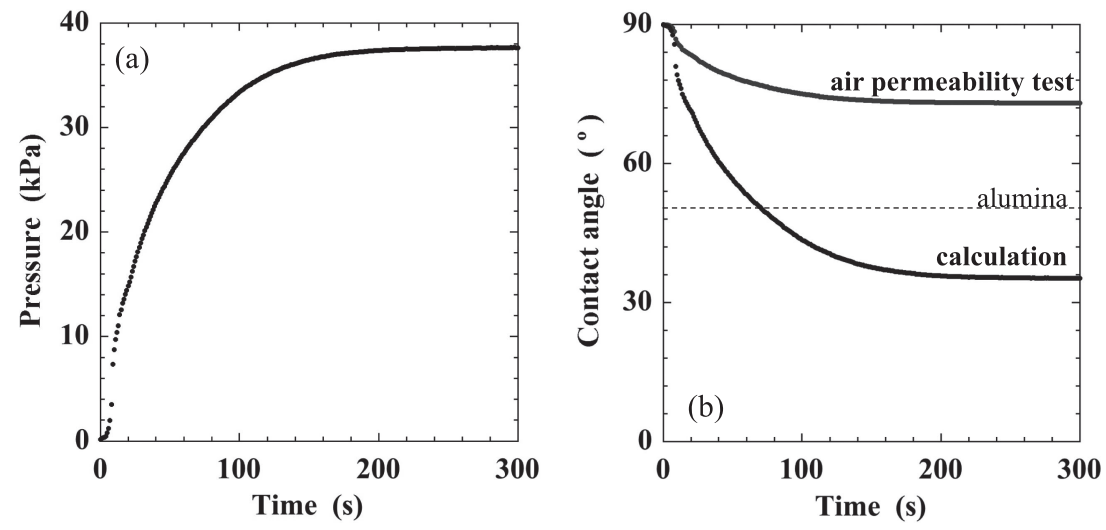

(c)
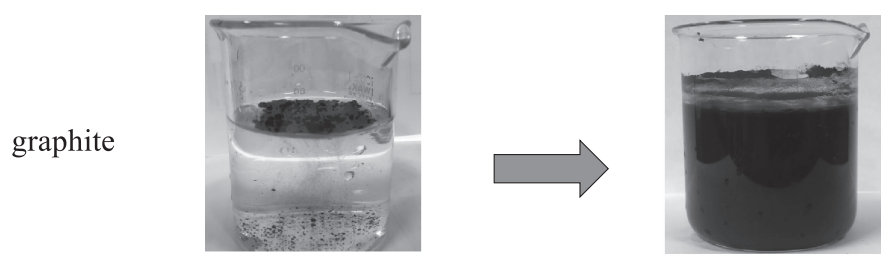

stirring
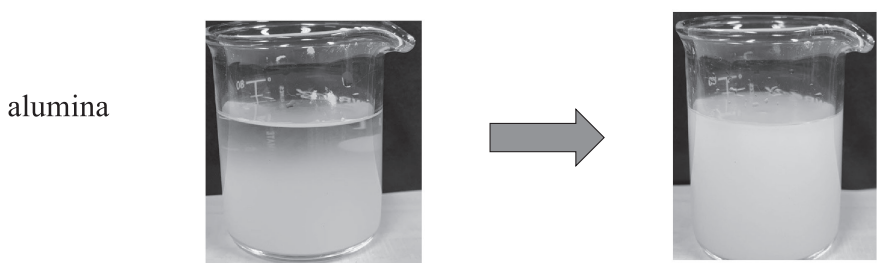

Fig. 15 Results of graphite powder, (a) time change of pressure, (b) time change of contact angle, and (c) appearance when soaked in deionized water. 
equilibrium was $35.2^{\circ}$, whereas the contact angle was $73.9^{\circ}$ when using the specific surface area determined via the air permeation test, i.e., $2.10 \times 10^{4} \mathrm{~m}^{-1}$. Based on the graphite powder dispersion test, most of the graphite powder floated on the water surface and then settled rapidly at the bottom of the beaker. Subsequently, the graphite powder was suspended when hand mixed, resulting in a slurry state. For the alumina abrasive powder used in this study with a contact angle of approximately $50^{\circ}$, the alumina powder almost dispersed in deionized water without stirring, indicating the higher wettability of the alumina powder to deionized water. Hence, it can be concluded that the contact angle of $73.9^{\circ}$ calculated using the specific surface area determined via the air permeation test can be regarded as the contact angle of graphite powder because the latter dispersed partially in deionized water, although its wettability to deionized water was worse than that of alumina abrasive powder.

Based on the experimental results for the glass beads, graphite, and alumina abrasive powder, it can be concluded that determining the specific surface area via the air permeation test is important for calculating the contact angle.

\section{Conclusions}

A device and technique for determining the advancing contact angle and contact angle were proposed. Using our developed device and technique, the amount of powder required for testing can be reduced to approximately $1.0 \mathrm{~cm}^{3}$, and the test can be performed in less than $1500 \mathrm{~s}$.

By comparing the conventional tapping method and the shearing and compressing method, it was demonstrated that the contact angle can be determined with high reproducibility using the latter method.

Furthermore, it was revealed that the contact angle can be determined precisely using the specific surface area determined via the air permeation test.

\section{Acknowledgements}

Part of this study was financially supported by the Japan Science and Technology (JST) Agency's Adaptable and Seamless Technology Transfer Program, Target-driven R\&D (A-STEP) Stage I, Industry Needs Response Type, "High Performance of Ceramics and Manufacturing Process" JPMJTS1618, Matching Planner Program, MP27115658343, and a research grant from The Information Center of Particle Technology, Japan. The authors are grateful to Mr. Kenta Kitamura and Mr. Naoya Iwata for their assistance with the experiments.

\section{REFERENCES}

1) A. Alghunaim, S. Kirdponpattara and B.Z. Newby: Powder Technol. 287 (2016) 201-215

2) K. Matsumoto et al.: Funtai Nanoryushi no Sousei to Seizo Syorigijyutsu, (Techno System, Tokyo, 2014) pp. 55-70.

3) M. Lazghab, K. Saleh, I. Pezron, P. Guigon and L. Komunjer: Powder Technol. 157 (2005) 79-91.

4) A. Alghunaim and B.Z. Newby: Colloids Surf. A 492 (2016) 79-87.

5) L. Galet, S. Party and J. Dodds: J. Colloid Interface Sci. 346 (2010) $470-475$.

6) K. Takebayashi and K. Tsuji: Industrial Machinery 11 (2011) 20-22.

7) K. Tsuji, K. Takebayashi and S. Sasabe: Japanese Unexamined Patent Application Publication No. 2014-55827 (2014).

8) K. Nakamoto, N. Someya and Y. Hoshino: Japanese Unexamined Patent Application Publication No. 2011-122960 (2011).

9) E.W. Washburn: Phys. Rev. 17 (1921) 273-283.

10) K. Tanaka and M. Koishi: J. Jpn. Soc. Colour Mater. 49 (1976) 22-28.

11) W. Bigui, C. Qing and Y. Caiyun: J. Colloid Interface Sci. 376 (2012) 307-311.

12) A. Depalo and A.C. Santomaso: Colloids Surf. A 436 (2013) 371-379.

13) L. Susana, F. Campaci and A.C. Santomaso: Powder Technol. 226 (2012) 68-77.

14) T.T. Chau: Miner. Eng. 22 (2009) 213-219.

15) D. Diggins, L.G.J. Fokkink and J. Ralston: Colloids Surf. 44 (1990) 299-313.

16) K.P. Hapgood, J.D. Litster, S.R. Biggs and T. Howes: J. Colloid Interface Sci. 253 (2002) 353-366.

17) The Society of Powder Technology, Japan, ed.: Funtai Kogaku Sosho No. 1, Funtai no Kiso Bussei, (Nikkan Kogyo Shimbun, Tokyo, 2005) pp. 100-102.

18) S. Fukushima: Shikizai 44 (1971) 382-387.

19) J. Tsubaki, T. Mori, H. Yamakawa, H. Mori and H. Hirose: J. Soc. Powder Technol., Japan 39 (2002) 339-345.

20) J. Tsubaki, T. Mori, H. Yamakawa, H. Mori and H. Hirose: J. Soc. Powder Technol., Japan 39 (2002) 800-805.

21) The Society of Powder Technology, Japan, ed.: Funtai Kogaku Sosho No. 1, Funtai no Kiso Bussei, (Nikkan Kogyo Shimbun, Tokyo, 2005) pp. 20-21.

22) The Society of Powder Technology, Japan, ed.: Funtai Kogaku Sosho No. 1, Funtai no Kiso Bussei, (Nikkan Kogyo Shimbun, Tokyo, 2005) pp. 34-35.

23) The Society of Powder Technology, Japan, ed.: Funtai Kogaku Sosho No. 7, Funtaiso no Sousa to Simyure-shon, (Nikkan Kogyo Shimbun, Tokyo, 2009) pp. 82-83.

24) The Society of Powder Technology, Japan, ed.: Funtai Kogaku Sosho No. 7, Funtaiso no Sousa to Simyure-shon, (Nikkan Kogyo Shimbun, Tokyo, 2009) pp. 84-86.

25) The Society of Powder Technology, Japan, ed.: Funtai Kogaku Bennran, (Nikkan Kogyo Shimbun, Tokyo, 1998) pp. 185-187.

26) X. Li, X. Fan and S. Brandani: Chem. Eng. Sci. 117 (2014) 137-145.

27) E. Al-Zaidi and X. Fan: Colloids Surf. A 543 (2018) 1-8.

28) The Society of Powder Technology, Japan, ed.: Funtai Kogaku Sosho No. 1, Funtai no Kiso Bussei, (Nikkan Kogyo Shimbun, Tokyo, 2005) pp. 37-38.

29) T. Yoshimi, Y. Ishiyama and F. Tomita: J. Robotics Soc., Japan 18 (2000) 1180-1183. 